\title{
Advances and challenges in postabortion care operations research: Summary report of a global meeting
}

Dale Huntington

Follow this and additional works at: https://knowledgecommons.popcouncil.org/departments_sbsr-rh

Part of the Demography, Population, and Ecology Commons, Health Services Research Commons, and the International Public Health Commons How does access to this work benefit you? Let us know!

\section{Recommended Citation}

Huntington, Dale. 1998. "Advances and challenges in postabortion care operations research: Summary report of a global meeting." New York: Population Council. 
Advances and

Challenges in

Postabortion Care

Operations Research

Summary Report of a Global Meeting

(1) Population Council 


\section{Advances and Challenges in Postabortion Care Operations Research}

\section{Summary Report of a Global Meeting}

19-21 January 1998 New York

\section{Prepared by \\ Dale Huntington}

\section{Coordinating Committee Members}

Meeting Coordinator Africa OR/TA Project ANE OR/TA Project INOPAL Project Ipas

Ebert Program
Dale Huntington

Ian Askew

M. E. Khan, John Townsend

James Foreit

Janie Benson

Karen Stein 


\author{
Population Council \\ One Dag Hammarskjold Plaza \\ New York, New York 10017 \\ tel 212-339-0500 \\ fax 212-7556052 \\ email pubinfo@popcouncil.org \\ www.popcouncil.org
}

The Population Council is an international, nonprofit, nongovernmental institution that seeks to improve the wellbeing and reproductive health of current and future generations around the world and to help achieve a humane, equitable, and sustainable balance between people and resources. The Council conducts biomedical, social science, and public health research and helps build research capacities in developing countries. Established in 1952, the Council is governed by an international board of trustees. Its New York headquarters supports a global network of regional and country offices.

The Africa OR/TA, Asia and Near East OR/TA, and INOPAL projects are funded by the Office of Population of the US Agency for International Development under contracts No.

DPE-3030-C-00-3008, DPE-C-00-90002-10, and CCP-C-00-95-00007-00 (respectively).

Copyright (C) 1998 by The Population Council, Inc.

Any part of this report may be copied or adapted to meet local needs without permission from the Population Council, provided that the parts copied are distributed free or at cost (not for profit) and that the source is identified.

Any commercial reproduction requires prior permission from the Population Council. The Population Council would appreciate receiving a copy of any materials in which the text or figures are used. 


\section{List of Figures}

Figure 1 Postabortion Care Chronology

Figure 2 Framework for Quality of Postabortion Care

Figure 3 OB/GYN Department Admissions During 30-Day Study in

Public-Sector Hospitals, Egypt

Figure 4 Effectiveness of Service Delivery Models: Percentage of Women Receiving Family Planning Counseling and Methods, Kenya 7

Figure 5 Percentage of Women Accepting Modern Contraception, Bolivia $\quad 10$

Figure 6 Postabortion Family Planning Counseling and Services Provided, Peru

Figure 7 Women's Experience of Pain During Postabortion Care, Mexico City

Figure 8 Framework for Introducing Program Improvements in Postabortion Care 


\section{Acknowledgments}

The organization of the Global Meeting on Postabortion Care Operations Research drew upon the creative and administrative talents of many individuals working in this field of women's reproductive health care. Members of an organizing committee included Ian Askew, Janie Benson, James Foreit, Dale Huntington, M. E. Khan, Donna Nager, and Karen Stein. This group was responsible for shepherding the development of the idea for the meeting from its earliest stages to fruition. The support and constructive advice provided by Sarah Harbison, Marge Horn, and Karin Ringheim were timely contributions that helped maintain a focus to our thoughts. A great number of individuals assisted in the logistical arrangements for the meeting-far too many to name here. The following colleagues deserve special mention, particularly as the site of the meeting was changed from Egypt to New York: in New York, Beth Levine and Donna Nager; in Nairobi, Julie Solo; and in Cairo, Sahar Hegazi and Sharon Omar. The publication of this Summary Report was achieved in collaboration with Robert Heidel and Christina Tse in the Population Council's New York office. The manuscript was reviewed by Janie Benson, Ronnie Johnson, Tim King, and Karen Stein, whose comments contributed greatly to the final product. Beyond the intellectual and creative contribution made by these individuals and the authors of the meeting's papers, there is a shared ideology among many of us about the importance of advancing improvements in this neglected area of women's health care. It is hoped that this report not only conveys this sense of purpose but also encourages others to pursue improvements in the quality of postabortion care services. 


\section{Introduction}

Women who have experienced complications from incomplete abortion are among the most neglected of reproductive health care patients. The medical care that is provided to them most commonly involves the use of an antiquated dilation and curettage $(D \& C)$ technique, often under general anesthesia. Manual vacuum aspiration (MVA) is not widely available in many devel oping countries, even though MVA use during the first trimester (with local anesthesia) has been demonstrated to reduce the health risks of the patient, lower the hospital's costs, and lead to quicker recovery. Too often, scant attention is paid to other health conditions with which the patient presents - for example, reproductive tract infections, sexually transmitted diseases, and repeated miscarriages. In addition to the generally poor quality of medical care, interpersonal communication during the postabortion treatment is also substandard in most settings. Counseling about the medical procedure required and the course of postoperative recuperation is usually not provided. Linkages to family planning services - either by service provision during the postabortion hospital visit or by referral to nearby family planning clinics - are not a customary element of discharge procedures for most postabortion patients.

The change in the United States Government administration in 1992, followed by the recommendations of the 1994 International Conference on Population and Development (ICPD), lessened constraints on research surrounding issues of induced abortion and the improvement of postabortion medical services. The Population Council's A frica, A sia and Near East (ANE), and Latin America and the Caribbean (INOPAL) Operations Research and Technical Assistance (OR/TA) projects responded quickly to this new field of research. The Africa and INOPAL OR/TA projects initiated subcontractual arrangements with I pas to carry out operations research studies on postabortion care in their regions. In Francophone Africa collaborative work with JHPIEGO has been undertaken. The ANE OR/TA project worked with the Population Council's Ebert Program, AVSC International, and Ipas on studies in Egypt and Turkey, while Council staff in India conducted comprehensive reviews of postabortion service availability and quality using existing data sources. In addition to these studies, postabortion operations research has been conducted by other USAID collaborating agencies and multilateral organizations (such as UNFPA and the European Union) and private foundations.

A Global Meeting on Postabortion Care: Advances and Challenges in Operations Research was held at the Population Council's New York office on 19-21 January 1998 to review progress made by the three

Postabortion care is defined as a service delivery strategy built around three elements:

- Emergency health services (treatment of complications of spontaneous or unsafely induced abortion)

- Postabortion family planning counseling, referral, and services

- Linkages to other reproductive health care services 
regional operations research projects in improving the delivery of postabortion care. The resources of the three regional operations research contracts were pooled, and, in collaboration with I pas and the Ebert Program, approximately 65 researchers, senior program managers, and government officials from A frica, Latin A merica, the Middle E ast, and Southeast A sia were convened. (A list of participants, including authors of papers discussed below, appears at the end of this report.)

Three objectives guided the planning of the meeting: (1) review progress in the development of operations research methodologies pertaining to postabortion care; (2) identify elements in the design of new postabortion care services; and (3) suggest future areas for postabortion care operations research. The meeting was organized around presentations of 20 papers that had been written and distributed to all participants several weeks earlier. Discussants for each session presented critical syntheses of the papers and indicated directions for future operations research studies. This report presents a summary overview of the principal themes and key points drawn from the papers and discussions, organized according to the theme of each session. Readers are referred to the authors of each paper for more information or copies of individual works.

\section{Defining the I ssues and the Magnitude of the Public Health Problem of Unsafe Abortion}

The meeting opened with a definition of postabortion care and a discussion of the public health problem of unsafe abortion. Forrest Greenslade reviewed the development of postabortion services and the introduction of vacuum aspiration instruments as a catalyst for changing clinical practices (Greenslade et al.).* The postabortion care initiative, an international effort founded on a public health perspective of women's reproductive heal th, focuses on the rapid transfer of knowledge and materials to reduce high rates of maternal mortality and morbidity from unsafe abortion. Although some public health professionals worldwide have been working on the issue of unsafe abortion for decades, the sequence of events beginning in 1982 (shown in Figure 1) draws attention to the important contribution made by the postabortion care concept to the field of women's reproductive health.

The elaboration of a postabortion strategy within a quality of care framework has clearly facilitated its development (see Figure 2). The reliance upon concepts drawn from the dominant paradigm for evaluating family planning programs makes the approach toward improving postabortion medical services immediately applicable to both researchers and program managers. The introduction of a new technology, manual vacuum aspiration, has been used to upgrade clinical practices related to pain control and prevention of infection

*Parenthetical references are to papers presented at the meeting and listed on pages 31-32. 


\section{Figure 1}

\section{Postabortion Care Chronology}

1982 I pas initiates demonstration training projects for treatment of abortion complications in Mexico

1984 UN International Conference on Population in Mexico City "chills" the field

1985 WHO sponsors International Meeting on Prevention of Maternal Mortality

1986 WHO Technical Working Group lists vacuum aspiration (both electric and manual) as an essential obstetric procedure

1987 Safe Motherhood Conference on Better Health for Women and Children through Family Planning held in Nairobi

1990 I pas emphasizes postabortion family planning. Tbilisi Conference held, "F rom Abortion to Contraception"

1991 I pas launches Postabortion Care (PAC) Initiative as a critical element of its strategic plan

1992 "Meeting Women's Needs for Postabortion Family Planning: Framing the Questions," Issues in Abortion Care (I pas)

1993 Bellagio Conference on Postabortion Family Planning (Ipas, Population Council, IPPF, South to South Cooperation in Reproductive Health); "Mexico City Policy" overturned, field thaws somewhat; PAC Consortium founded by Ipas, Pathfinder International, AVSC International, IPPF, JHPIEGO; series of meetings at USAID; PAC highlighted at USAID meetings

1994 "Postabortion Care: A Women's Health Initiative to Combat Unsafe Abortion," Advances in Abortion Care (I pas); USAID announces postabortion care as a reproductive health priority; Paragraph 8.25 of Cairo ICPD Programme of Action provides global support for PAC

1995 UN World Conference on Women in Beijing emphasizes public health issue of unsafe abortion; International Donors Conference on "Implementing Reproductive Health Programs" highlights postabortion care; WHO publishes Complications of Abortion: Technical and Managerial Guidelines for Prevention and Treatment; postabortion care research incorporated in INOPAL, Africa OR, ANE OR, and MotherCare

1996 Postabortion care becomes a mainstream activity of the reproductive health and family planning community

1997 "Care for Postabortion Complications: Saving Women's Lives" published in the series Population Reports

Source: Greenslade et al. 


\section{Figure 2}

Framework for Q uality of Postabortion Care

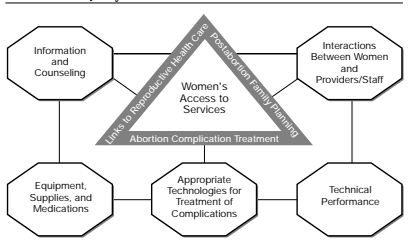

Source: Greenslade et al.

as well. A number of improvements in interpersonal communication practices, chiefly involving information and counseling, accompany the technology introduction, drawing providers' attention to alternative case management procedures that involve a more womancentered approach to postabortion care.

The sensitive nature of abortion, particularly in settings where it is legally restricted, will continue to impose constraints on the postabortion care initiative. "A critical first step is for policymakers to understand and acknowledge the essential nature of the link between women's health and postabortion care, and the realization that postabortion care services are incomplete without effective family planning efforts" (Greenslade et al.).

Defining the magnitude of the public health problem of unsafe abortion is a first step toward allocating resources to programs that will improve postabortion services. Induced abortion has proven to be one of the most difficult health care practices to study, even in settings where it is legally available, due to pervasive social and religious norms surrounding abortion. The survey measurement of abortion is fraught with under-reporting, and secondary analyses that construct abortion rates provide little opportunity for investigating related morbidity. Hospital-based studies are an alternative to community surveys, although their implementation must involve upgrading routinely collected statistics.

Ezzeldin Osman Hassan described the postabortion caseload in Egyptian public-sector hospitals as an example of policy-relevant operations research ( $H$ untington et al.). This nationally representative study was conducted using random sampling procedures covering approxi- 
mately 15 percent of public-sector hospitals in Egypt. Among the 22,656 admissions to $O B / G Y N$ departments during the continuous 30-day study, 19 percent of patients were admitted for treatment of an induced or spontaneous abortion (see Figure 3). Projections yielded an estimated induced abortion rate in Egypt of 14.75 per 100 pregnancies. Dilation and curettage $(D \& C)$ under general anesthesia is the principal surgical technique used in the treatment of incomplete abortions in Egypt. The mean gestational age of the lost pregnancies is 10.8 weeks, and a large majority ( 86 percent) were lost at 12 weeks or less, clearly indicating the appropriateness of introducing manual vacuum aspiration instruments for postabortion treatment in Egypt.*

A great deal can be learned about abortion practices by examining the presenting symptoms and range of complications among postabortion patients. The Egyptian caseload study revealed that although 14 percent of the patients arrived at the hospital suffering from excessive blood loss, only 1 percent exhibited one or more signs of trauma, and 5 percent presented with one or more signs of infection. These and other findings suggest that largely benign medical practices are most commonly being used to induce abortion, including inappropriate use of emergency contraceptive methods after unprotected sexual relations.

The Egyptian study has demonstrated that hospital-based investigations can be modified to collect high-quality data that will accurately describe current medical practices and patient characteristics. The use of abbreviated medical record forms in hospitals can be considered as a practical alternative to community-based research on abortion. The study findings were reported to have been used to stimulate policy debate and the development of programs to improve the medical treatment provided to postabortion patients in Egypt.

*MVA instruments are most effective with early gestational age pregnancies and are recommended for use during the first trimester in most settings.

\section{Figure 3 \\ OB/GYN Department Admissions During 30-Day}

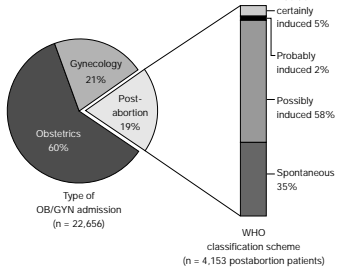

Source: Huntington et al.
Abortion 


\section{Creating N ew Postabortion Services: Intervention Design and Implementation}

The improvements made in the medical treatment of incomplete abortion since the creation of the postabortion care initiative have been closely based on the approach elaborated by Ipas (Greenslade et al.). The general approach in all of the operations research studies described here has been to stress the holistic treatment of the patient, as opposed to improving a single aspect of services (e.g., the use of MVA instruments). Attention is given to improving both the technical competence with new surgical procedures and the interpersonal communication that all categories of staff have with the patient. M ost commonly the introduction of MVA instruments changes a number of clinical practices. In some settings the physical location of the postabortion treatment area has been moved. This session's papers, drawn from studies in A frica and Latin America, presented regional variations on this basic approach to the creation of improved postabortion care services.

Julie Solo and colleagues (Solo et al.) reported on a study in Kenya that examined three service delivery models in hospital settings, each based upon holistic case management procedures for postabortion patients but with alternative approaches to providing family planning services. In two of the models contraceptive methods are provided in the OB/GYN inpatient department. One variation of this model has $\mathrm{OB} / \mathrm{GYN}$ staff providing contraceptives, and the second variation has $\mathrm{MCH} / \mathrm{FP}$ outpatient staff coming to the hospital's $\mathrm{OB} / \mathrm{GYN}$ department to provide the methods. The third experimental model is based upon the referral of postabortion patients from the $\mathrm{OB} / \mathrm{G} Y \mathrm{~N}$ department to the hospital's MCH/FP clinic for family planning services (patients who indicated a desire for contraceptives were escorted to the family planning clinic prior to discharge). A broad range of outcome indicators was measured using a pre-test/post-test study design in each of the six hospitals studied. These included measures of the feasibility of improving services, the costs associated with the changes, the acceptability of the service delivery arrangement (to both providers and patients), changes in the quality of care provided, and the relative effectiveness of the three models in increasing family planning use.

Solo and her colleagues reported that substantial changes in the quality of postabortion services were noticed in each of the sites (see Figure 4). The provision of family planning in the $O B / G Y N$ department by the same staff who provided postabortion care was the most effective in terms of reaching more women with counseling, increasing family planning acceptance, and providing contraceptive methods. The addition of family planning services to the inpatient $O B / G Y N$ department necessitated a reconfiguration of the physical space (for counseling and storage of contraceptives) that caused additional resources to be expended. There was some evidence that patients who sought family planning services in the $\mathrm{MCH} / \mathrm{FP}$ clinic did indeed receive higher-quality counseling than those patients who received counseling in the $\mathrm{OB} / \mathrm{GYN}$ department (indicating that additional training in interpersonal communication skills should be provided to staff on the wards). A large number of referred patients were lost to follow-up, however, thereby limiting the effectiveness of the model. 
The development of improved postabortion services in Francophone Africa is relatively new in comparison with the program experience in East Africa. A nita Ghosh described preliminary steps taken to introduce changes in the treatment of postabortion patients in Burkina Faso that are illustrative of the issues confronting programs in Francophone countries (Ghosh et al.). A series of consultative meetings served to develop a constituency for the postabortion care initiative. On-site assessments of the services in two government hospitals further demonstrated the need for improvements and consol-

Figure 4

Effectiveness of Service Delivery Models:

Percentage of Women Receiving Family

Planning Counseling and Methods, Kenya

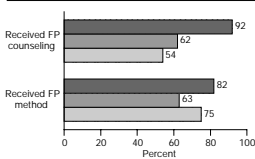

$\square$ Model 1 (from OBIGYN staff on ward) Model 2 (from FP staff on ward) Model 3 (from FP clinic)

Source: 5 ol o et al. idated support for introducing changes. Services in Burkina F aso were found to be neglected: national policy and standards of care for the treatment of incomplete abortion did not exist, family planning guidelines did not incorporate reference to postabortion contraceptive use, infection control procedures were deficient, and staff technical knowledge about postabortion complications and followup care was incomplete. A competency-based training program was developed for introducing changes in case management protocols, including the use of MVA and provision of family planning services. The compelling rationale for change in this program has been the need to upgrade clinical aseptic procedures. The focus on aseptic practices that are essential to the safe delivery of all OB/GYN services apparently has facilitated the introduction of changes related specifically to postabortion care.

A s in A frica, abortion in much of Latin A merica is legally restricted and the subject of pervasive religious and cultural sanctions. In this setting interventions have focused on improving provider-patient interactions so that postabortion patients are treated more compassionately, in addition to changing surgical procedures and other aspects of medical treatment. A presentation by Cecilia Garcia-Barrios on the work done in a large public hospital in Oaxaca, Mexico is revealing of regional variation in emphasis within the global postabortion care initiative (Langer et al.).

Oaxaca is the capital city of an impoverished, rural state in Mexico. The hospital in this study treats one or two postabortion patients daily, many of whom speak one of 20 local languages or dialects but do not understand Spanish (the language of the physicians). A quasi- 
Interpersonal Relations W orkshop in the Oaxaca, Mexico Postabortion Care Study

In order to sensitize providers to the needs of women who have undergone an abortion, all providers in the hospital's OB/GY N department participated in a 14-hour workshop on interpersonal relations. The workshop was designed to meet the following objectives:

- To improve the quality of care for the postabortion patient

- To promote a change of attitude among health care personnel toward more humane service delivery

- To value quality and human warmth as important tools in an integral care package

- To recognize the woman behind every patient and accompany her during the recuperation process

- To reflect on the service vocation of health care professionals

Each of these themes was addressed through interactive talks, role playing, meditation, relaxation exercises, and imagery techniques.

Source: Langer et al., p. 12. experimental study designed to test service delivery improvements included data collection on a wide range of quality of care indicators. In addition, the study conducted in-depth interviews with staff and patients to assess their perceptions of changes in postabortion services. The intervention's essential steps were to: (1) modify hospital procedures to reduce waiting time, improve pain management, and ensure privacy; (2) switch from $D \& C$ to MVA; (3) improve patient-provider relations, including special emphasis on counseling about postabortion contraception; and (4) produce specially adapted printed materials to reinforce counseling. The Oaxaca study's emphasis on improving interpersonal communication, particularly the need to address class and language barriers between providers and ethnic minority patients, is in the forefront of postabortion care behavioral change interventions.

The results from the Oaxaca study reveal several positive changes in the treatment and care of postabortion patients. The amount of time, particularly post-operative waiting time, decreased substantially. The immediate acceptance of MVA instruments was al so evident: before the study only about 10 percent of the cases were treated with MVA, whereas after the intervention 78 percent of the appropriate cases were so treated. The results related to pain management were mixed. Although providers began to use a local instead of a general anesthetic more frequently after the study's intervention, clinical measures to relieve pain before and after the procedure were not affected - even though these measures had been repeatedly emphasized during the training and supervisory follow-up visits.

Remarkable changes occurred in the manner in which patients were treated in the hospital and in the quantity and frequency of information exchange as a result of efforts directed toward interpersonal communication skills. For example, "In general, doctors and nurses would take greater care in situating the patient on the operating table, and would use more 
kindness when indicating how the patient should adjust herself" (Langer et al., p. 17). One result of improved interpersonal communication was a significant increase in the percentage of women who accepted a postabortion contraceptive method (from 29 percent previously to 58 percent following the study) and in the percentage of women who received the method at the hospital before discharge (from 29 percent to 57 percent). The authors note that despite these impressive gains, a degree of mistrust and fear remained in the relations between providers and patients. Overcoming culturally bound behaviors and beliefs in the process of providing medical care will require diligence and effort. The study in Oaxaca is noteworthy for addressing these issues.

The influence of the caregiving environment on the services provided to postabortion patients was also evident in the second study from Latin A merica discussed in this session. J uan Diaz reported on how legal sanctions against abortion have negatively affected the care given to postabortion patients in three public-sector hospitals in Bolivia. Investigators had identified such problems as the routine interrogation of postabortion patients to identify cases of illegal abortion, the charging of higher fees to patients who present with signs of induced abortion (fees that are prohibitively high for many women, thus causing delays in seeking care), and other practices related to substandard case management protocols. The Ministry of Health in Bolivia recognized these issues and asked the Population Council to conduct a pilot study to identify feasible improvements in clinical practices that would result in better quality of care and increased family planning use by postabortion patients.

In contrast to all of the other postabortion care operations research studies reported on in the meeting, the Bolivia study did not change the surgical practice of $D \& C$ in favor of MVA. Change was introduced instead by moving the physical location of the treatment area into a newly refurbished room. The holistic management of the patient was emphasized, including stress on interpersonal communication and referral for related services (including contraceptive methods). The results clearly showed substantial improvements in providers' technical competence with postabortion treatments and in contraceptive use following an abortion (see Figure 5). These increases in technical knowledge resulted in medical staff providing more frequent counseling, with a greater breadth of information being discussed with postabortion patients. The effects of the training program's emphasis on value-free interpersonal behavior are shown in several indications that providers' treatment of women became more compassionate and caring. One consequence of these improved communication skills is that the study sites began to receive more adolescent patients as the hospital's improved quality of care became known to the surrounding communities. There were substantial increases in the acceptance of family planning among postabortion patients, from almost no acceptors before the study to 46 percent of patients in one site and 81 percent of patients in another site beginning use of a contraceptive method after improved postabortion care was linked with subsequent use of family planning.

The authors note that although there have been repeated examples of successful pilot studies to improve the quality of postabortion care in Latin A merica, the results are rarely 


\section{Figure 5}

\section{Percentage of Women Accepting Modern}

\section{Contraception, Bolivia}

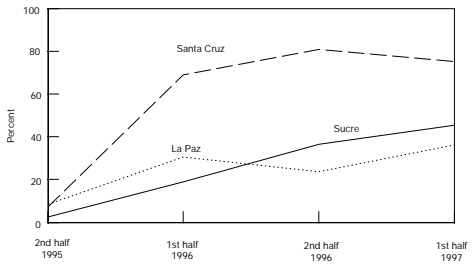

Source: Diaz.

scaled-up or sustained. They conclude that "the lack of effective implementation of these programs [is] derived mostly from social and political reasons rather than technical ones" (Diaz et al., p. 13). Three factors inhibited the development of integrated postabortion services within a family planning and reproductive health care program in this study: (a) legal and administrative constraints that force women seeking abortion services into clandestine settings where related reproductive health care services are unavailable; (b) women's low socioeconomic status and normative restrictions on abortion, which combine to make the health care needs of these women a low governmental priority; (c) the longstanding influence of the Mexico City policy that was, until recently, a restrictive force in Latin A merica. The ability to improve access to services for the treatment of postabortion complications has been shown to be an important and feasible first step in redressing some of these constraints, particularly by allowing women to seek earlier treatment, thereby reducing their health risks.

The discussant for this session's papers, Khama Rogo, emphasized the need for community-based approaches for creating new services and reducing the risks from unsafe abortion. The clinical focus of the postabortion care initiative has led to a somewhat limited focus in the design of new services, with the result that non-hospital-based and private-sector approaches have not been fully examined. In particular, the role of the private sector needs to be addressed in future postabortion care programs. The Safe Motherhood Initiative has broadly included both clinical and community-based interventions for all of its elements 
except postabortion care; clearly. Future studies need to examine the provision of services in settings other than large, public-sector hospitals.

\section{M easuring the Quality of P ostabortion Care}

Coherence across geographic settings on such issues as study design and approaches to measurement has been nurtured by operations research project staff since the 1994 ICPD. Early postabortion care studies conducted in Turkey and Egypt* provided guidelines on indicators and model data collection instruments that have been adapted in subsequent studies. The standardization of postabortion care indicators has been facilitated by congruence of study design, data collection methods, and the elements of improved care reviewed in the previous section. For example, the reliance upon pre- and post-test research designs has focused investigators' attention on developing exit interview questionnaires. The bundling of clinical and interpersonal practices around the introduction of MVA technology has linked the selection of indicators to a standard intervention for improving services. The DATAPAC Project of I pas and INOPAL will contribute to the creation of a core set of instruments by researchers worldwide. Although the results from the studies presented at the J anuary meeting suggest an emerging standardization in measuring the quality of postabortion services, country-specific variations are evident as well.

An example of the current state of the art for measuring postabortion service quality is the study in Peru by J anie Benson and colleagues of an integrated postabortion care model in a public hospital (Benson et al.). There was evidence that services were too costly and of poor quality. The Ministry of $\mathrm{Health}$ in Peru took note of these deficiencies and requested an operations research study to examine the effects of introducing comprehensive postabortion services on clinical practices and the utilization of resources. The introduction of an integrated model for postabortion services required several modifications in the hospital's structure, including: (a) shifts in the case management protocols for postabortion treatment, (b) reducing the fees charged to patients for services, (c) modifying the type of medical supplies, equipment, and commodities used in postabortion services (with resulting changes in the hospital's logistical support mechanisms), (d) creating new job descriptions as staff responsibilities were modified, and (e) making several improvements in the hospital's physical infrastructure where patients are treated.

Changes in the provision of postabortion services resulted in marked improvements that were tracked using a quality of care framework. $†$ This model emphasizes the collection of data on indicators of providers' technical competence and the interpersonal communication

*Dale H untington et al. 1996. "The quality of abortion services in Turkey," International J ournal of Gynecology and Obstetrics 53: 41-44. Dale Huntington et al. 1995. "Improving the medical care and counseling of postabortion patients in Egypt," Studies in Family Planning 26, no. 6: 350-362.

tJ udith Bruce. 1990. "Fundamental elements of the quality of care: A simple framework," Studies in Family Planning 21, no. 2: 61-91. 


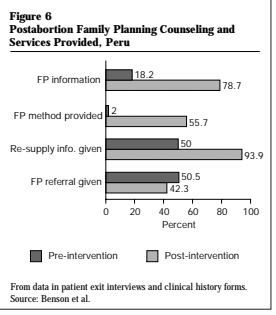

that occurs during the hospitalization. For example, preliminary findings from this study indicate that the utilization of MVA increased from nil to 91 percent of clinically appropriate patients. The proportion of patients who reported receiving elements of high-quality care rose substantially after the intervention (see Figure 6). For example, the proportion of patients who received information about their diagnosis increased from 11 percent before the study to 28 percent after; about their treatment, from 10 percent before the study to 46 percent after; and about family planning methods, from 18 percent

to 79 percent. The length of stay for postabortion patients was reduced, from just over 33 hours to approximately 6 hours. This substantial reduction, when understood as being accompanied by a change in the utilization of resources during the stay, prompted the hospital administration to summarily reduce the fees charged to patients by one-half. The authors conclude that the support of key officials was essential to the success of this pilot program. The production of results linked to a well-recognized quality of care framework was a critical element in garnering support for improving the caregiving process.

In studies such as the integrated model of postabortion services in Peru and elsewhere, substantial improvements in service quality have been made within a relatively short time. The introduction of MVA under lower levels of pain medication, coupled with improvements in counseling and other clinical practices, has been shown to result in greater patient knowledge and increases in family planning use. The effective management of pain for postabortion patients has been improved in most studies, but this area of case management remains a difficult aspect of service quality because some women still report feeling severe pain. The measurement of women's perceptions of pain is a complex undertaking as expressions of pain reflect the influence of several stimuli, both environmental and physiological.

An innovative study on women's experience of pain during postabortion care was conducted by J aime Fuentes Velazquez and colleagues as part of a larger investigation comparing three models of postabortion care in six large hospitals in metropolitan Mexico City (Fuentes et al.). In the first model, MVA is used with a local para-cervical block accompanied by analgesics or sedatives if needed for pain control, along with patient counseling throughout the treatment. In the second and third models, sharp curettage $(D \& C)$ is 
employed with heavy sedation, hypnotics, and analgesics for pain control that essentially renders the patient unconscious. The second model includes patient counseling, even though there are periods during the treatment when women are unconscious due to the heavy sedation. The third model is in effect the existing service, as it includes no innovative treatment or counseling (see Figure 7). Women's self-reports of the type, location, and intensity of pain, as well as their descriptions of their emotional state, were collected. In addition, a "pain behavior observation" technique was used to record precoded physical manifestations of pain (such as facial expressions, vital signs, body position, etc.) before, during, and after the treatment procedure; a final exit interview was conducted immediately prior to discharge from the hospital to assess pain felt at that point.

Preliminary results drawn from 144 women reveal that most reported mild to moderate pain during the pre-procedure period. U pon discharge from the hospital all of the women felt pain, but those who had received only heavy sedation (Model 3) felt the most pain, while those who had been treated with MVA under local anesthesia, plus intensive counseling, reported feeling the least amount of pain (Model 1). Assessment of patients' self-reported emotional state focused on the largely negative dimensions of being nervous, worried, sad, and depressed - a measurement technique that drew several comments from participants as omitting other, more positive psychological states relating to relief or self-worth. In any case, the study noted a positive effect of training providers on how to manage their patients' emotional state. Findings that reported on women's expectations of pain reveal that women

Figure 7

Women's Experience of Pain

During Postabortion Care, Mexico City

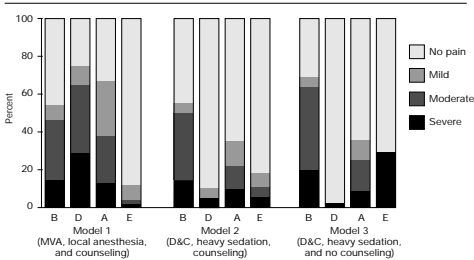

$\mathrm{B}=$ before treatment $\quad \mathrm{D}=$ during treatment

A $=$ after treatment

$\mathrm{E}=$ exit interview

Source: Fuentes et al. 
who were treated with MVA under local anesthesia consistently reported more pain than was recorded by the observers, whereas patients treated with curettage reported a greater frequency of sharp and burning pain. All of the patients believed they were receiving more pain medication than they had actually been given.

The study concludes that although all postabortion patients reported some pain during the caregiving process, it was most notable during the pre-procedure stage. Training providers in counseling and supportive skills could alleviate some of this pain. Even though heavy sedation will remove any sensation of pain during the procedure, those patients who received lower levels of sedation were most likely to report less pain after the procedure. The Mexico study has demonstrated that a great deal of pain is still being experienced unnecessarily by postabortion patients. The results clearly suggest that more needs to be done in training providers in the effective use of pain medication throughout the process of postabortion care.

The presentation of operations research studies that measured the quality of postabortion care moved at this point to the assessment of the functioning of health care systems. Situation analysis studies of abortion services in India and Turkey were presented next. In both settings study instruments based on the Population Council's situation analysis methodology were utilized to evaluate the quality of induced abortion services. A bortion is legally available in both countries, with some differences in the restrictions imposed in the two settings.

Medical termination of pregnancy (MTP) was legalized in India in 1972 for broad social and medical reasons. Since that time the availability of services in rural areas has largely been limited to community health centers and rural hospitals; recently a small proportion of primary health centers have begun providing MTP services. Most of the estimated 6.7 million abortions each year in India are performed in sites other than registered government institutions, often by untrained persons in unhygienic conditions. Although a review of the national statistics reveals that MTPs increased by 46 percent in the decade 1981/82-1991/92, a plateau was reached in 1985 after which the annual number of procedures has been stable at about 600,000 abortions, or about 10 percent of the total number of abortions performed nationwide. The average number of MTPS per registered clinic has declined from 111 in 1981/82 to 89 in 1991/92. The paper by M. E. K han and his colleagues analyzes system-wide indicators of MTP service quality, so that the government can take corrective action to reverse the decline in the number of MTPS performed in public-sector facilities, through its new Reproductive and Child $\mathrm{H}$ ealth approach (K han et al.).

A situation analysis of abortion services was conducted in 751 clinics located in the states of Gujarat, Maharashtra, U ttar Pradesh, and Tamil Nadu (the population of these four states represents about 37 percent of India's total). The construction of the sampling frame revealed that MTP service sites are unevenly distributed and that there is a wide disparity among the states in the utilization of registered clinics. Interviews with over 500 physicians provided anecdotal evidence of an increase in the postabortion caseload as more women resort to MTP outside the legally sanctioned system. The study revealed that not all of the 
clinics registered for providing MTP services were functional: between 16 percent and 32 percent of the primary health centers that are approved for MTP have never offered the service. The principal reason for not offering MTP was the lack of a trained provider and functioning equipment, indicating shortcomings in the conduct of training as well as the difficulty of ensuring adequate training when the caseload of patients is quite low. Although linkages to family planning services were generally weak in Uttar Pradesh and $\mathrm{M}$ aharashtra and were declining in many sites, in Tamil Nadu the acceptance of a family planning method, notably sterilization, was a precondition for performing MTP. Overall, the failure to integrate MTP and family planning in an appropriate and ethically sound manner is an aspect of the program that needs to be improved.

A second application of the situation analysis methodology, in Turkey, was reported by Levent Çagatay (Pile et al.). Induced abortion has been legally available in Turkey since 1983 for married women with a gestational age of ten weeks or less, with the consent of their husbands. Prior to the lifting of legal restrictions on abortion, consistent evidence indicated that abortion rates had increased steadily throughout the 1960 s and 1970 s, with a concomitant rise in the contribution of abortion-related complications to maternal mortality rates. Despite this evidence the Turkish medical community gave little support to the case for legalized abortion, most likely because of economic benefits derived from performing expensive illicit abortions. This economic incentive, although reduced with the legalization of abortion, has continued to hinder efforts to link family planning and abortion services. This is particularly important given that the most popular method of family planning in Turkey remains withdrawal, which accounts for almost two-thirds of the method failures that result in an aborted pregnancy. Given this background it is not surprising that in 1993 one out of every five pregnancies ended in an induced abortion, and that between 28 and 40 percent of Turkish women have had at least one induced abortion.

The 1994 situation analysis of abortion services was conducted in 16 large hospitals in seven provinces of Turkey. These facilities provided 48 percent of all abortions reported by the Turkish Ministry of Health in 1994. Data collection methods focused on a comprehensive listing of quality of care indicators: an inventory of all available equipment, supplies, and materials; staff and

"Over the past several years a few institutions in Turkey have successfully piloted programs designed to improve family planning counseling and services provided to abortion clients. By linking abortion and perinatal services to already existing family planning services, by building the capacity of staff to provide high-quality information and counseling, and by taking advantage of opportunities to increase men's use and support of contraception, these facilities have been able to make a difference in the lives of the women and men they serve. One of the most important characteristics shared by ... these institutions ... is a commitment or 'political will' on the part of the staff and administrators to provide postabortion family planning."

Source: Pile et al., p. 29. 
patient interviews; and standardized observations of all procedures. The results reveal several strengths as well as deficiencies in the Turkish program.

The distribution of providers who perform abortions shows that general practitioners account for close to half of the procedures, even though as a group they represent only onethird of all providers. OB/GYN specialists are less likely to perform abortions in the public sector, leaving the procedure to general practitioners while they provide abortions in their private practices. The availability of abortion services is additionally limited by the number of sites that offer the procedure. Overall in Turkey "only 27 percent of public-sector hospitals routinely provide abortion services and only $2 \mathrm{MCH} / \mathrm{FP}$ centers perform abortions," even though in theory all general hospitals and government MCH/FP centers are permitted to provide such services (Pile et al., p. 10).

The results from the factual knowledge test administered to providers and the observations of procedures reveal that physicians in public-sector facilities are quite competent in the surgical techniques of abortion, relying upon vacuum aspiration, but many of the ancillary skills such as medical evaluation/screening, counseling, and infection prevention measures are weak or nonexistent. Pain control medication was found to be severely underutilized, in part because earlier case management protocols had de-emphasized the need for general anesthesia (due to increased health risks) without drawing attention to other types of pain control medication. The study showed that 48 percent of abortion patients did not receive any medication for pain during the procedure; correspondingly, 37 percent of the patients reported experiencing extreme pain and an additional 46 percent reported feeling moderate pain. Because of the lingering economic disincentives to providing family planning (repeat abortions are a source of income for specialists), the findings related to linkages with the family planning program are not entirely surprising. Family planning use among Turkish abortion patients was low. Even though 84 percent of the abortions were done in settings that provided family planning methods, only 40 percent of the patients left the facility with a method.

An overview of the session's papers, by lan Askew, focused on the remarkable overlap in the selection of indicators for the measurement of quality of care. Wondering whether this congruence was the result of these indicators being universally relevant or whether it was due to networking among researchers, he called for an increased effort to identify alternative indicators that will expand our conceptual framework. Several promising areas for development stand out, including an urgent need to ground the measurement of quality of care within patients' concerns. New research is required that will investigate women's perceptions of abortion and postabortion care.* Additional work is also required to confirm that the selection of indicators responds to the needs of program managers. For example, although much of the work focuses on facility-level indicators that can be aggregated to create program indicators (as is the case with situation analysis studies), the use of these findings for program planning and

*A n example of this emerging area of inquiry is Dale Huntington, Laila Nawar, and Dallia A bdel-H edy. 1997. "Women's perceptions of abortion in Egypt," Reproductive Health Matters 9 (May). 
evaluation requires that operations research incorporate a dissemination and utilization plan into their activities. Askew's review concluded with a plea for studies that measure the impact of different levels of quality on longer-term reproductive health behaviors, including the reduction of morbidity related to incomplete abortions.

\section{Follow-Up Studies of Postabortion Patients}

The conduct of longitudinal follow-up studies of postabortion patients poses several challenges unique to the subject while also including many of the common difficulties of panel studies. The ethical obligation to protect the postabortion patient's right to privacy is a serious concern in the conduct of a follow-up study, particularly given that in most settings both the woman and the provider are subject to legal and social sanctions if they are discovered to have induced an abortion. The influence of cultural and societal norms further restricts the postabortion patient's open acknowledgment of the cause of her hospitalization. The potential for physical and psychological harm occurring to the postabortion patient if she participates in a follow-up study is therefore quite high. These considerations, in addition to heightening the attention given to building in safeguards for confidentiality and informed consent, will complicate the ability to ensure responses free from error in the follow-up interview.

A large prospective study of postabortion patients in Zimbabwe was discussed by Ronnie J ohnson (J ohnson et al.). The authors reported on several elements of the design and conduct of fieldwork that are indicative of issues confronting postabortion follow-up studies. The effect of attrition rates is one example that can be drawn from the fieldwork experiences in Zimbabwe.

At the baseline interview in Zimbabwe 1,776 patients were enrolled from the study's intervention sites and 1,114 patients were enrolled from the comparison group sites. Enrollment at the intervention sites occurred after postabortion services had been improved through a comprehensive training program. Thus the follow-up study measures the impact of changes in the quality of care on selected patient outcomes, including family planning use. Acceptance rates (for the follow-up interview) of 72 percent and 57 percent (in the two study groups) were encountered during the enrollment interviews. These women agreed to return to the hospital after $3,6,9$, or 12 months (depending on the level of the study in which they were enrolled- national or provincial; at the district level there was no follow-up interview). On these return visits, women would be reimbursed for transport and receive a modest sum for their lunch (investigators arranged to conduct home interviews of patients who did not return for the hospital-based interview). Preliminary data showed that at three months there was an average attrition rate of approximately 58 percent from the four sites reported on; at six months the attrition rate had increased to 63 percent of the original sample, although the fraction of women who dropped out between the third and six month was 
only 14 percent. These rates have left some of the sites with relatively few patients still enrolled in the study at its halfway mark of six months (one site is down from an initial 120 women to 27 women participating after six months). A lthough there was initially a high attrition, the proportion of women dropping out of the study has decreased substantially. J ohnson and coauthors consider the overall response rate fairly good and are optimistic about the study yielding meaningful results upon its completion in late 1998.

A second follow-up study, conducted in Egypt, was discussed by Nahla Abdel-Tawab and colleagues (A bdel-Tawab et al.). This study examined the effect of involving husbands on postabortion patients' recovery and subsequent contraceptive use while also maintaining the patients' right to privacy. An experimental post-test-only control group design was used to measure the effect of the intervention on husbands' level of involvement and on patient outcomes one month after discharge. Husbands in the intervention group received several pieces of information concerning their wives' health (based on formative research conducted earlier in Egypt): the need for rest and nutrition, warning signs, return to fertility, and the need for family planning methods. The effect of providing this information on the level of the husband's support (material and emotional), the patient's physical and emotional recovery, and the couple's contraceptive use was assessed through home interviews with the patients and group discussions with a few husbands.

Perhaps because of the shorter follow-up period and reliance upon home-based interviews, the Egyptian study had a lower attrition rate than the Zimbabwe study: of the 366 patients who agreed to participate in the study, 80 percent completed the home interview. Reaching men proved to be relatively easy, once the patient's informed consent had been obtained. The majority of husbands either accompanied their wives at admission or were present at discharge from the hospital. A positive effect of counseling on husbands' behavior and patients' recovery was evident. For example, patients whose husbands were counseled reported significantly lower levels of emotional distress related to the incomplete abortion than patients whose husbands were not counseled. The investigators concluded that the counseling of husbands should become an integral component of postabortion care programs and that informed consent procedures should be strictly enforced to protect the patient's right to privacy.

As a discussant for this session, Emma Ottolenghi emphasized the importance of investigating the medium- and long-term impact of postabortion service improvements. The ability of the studies from Egypt and Zimbabwe to address some of the barriers to conducting follow-up studies may be due, in part, to the superior quality of the services the women received, which could have resulted in the patients being more compliant. The studies draw attention to the need to include a broad range of outcome indicators for the follow-up that are demonstrably linked to the experimental interventions. For example, the Zimbabwe study suggested that the family planning intervention may have been more successful at delivering contraceptives than at providing information. An assessment of the intervention's effectiveness in improving counseling skills should include direct observation techniques 
that examine the quality of the interaction, and the follow-up interviews should probe into knowledge retention and attitudinal change, as well as reproductive health behaviors.

\section{Cost Studies of P ostabortion Care Services}

The cost-efficiency of the postabortion care initiative has been reported on previously.* These cost studies have suggested that considerable savings accrue with the introduction of MVA, and that most efficiencies are gained through reductions in the duration of hospital stay, less intensive use of hospital resources (materials and supplies), and more effective use of staff time. The methodology for assessing the treatment of postabortion patients used in these early studies was refined by Ipas through its collaboration with the Population Council's INOPAL project, and reports of two applications of the cost study methodology were presented at the J anuary meeting.

The I pas cost methodology is a standard approach to recording the utilization of resources and estimating a per-patient cost. Through an intensive review of a facility's financial, administrative, and personnel records, estimates are made of the costs of medical supplies, salaries, and relevant direct fixed costs. Overhead estimates are used to determine the average cost of bed use per minute and per day. Postabortion patients are also observed in order to assess the variable costs associated with their treatment. This time and motion study involves having trained observers use standardized checklists to record the amount of time spent by patients in each service department or treatment station, the time spent by medical and non-medical personnel in direct patient contact, and the types of supplies and medications used in the treatment of patients. By combining information taken from the review of hospitals' administrative data and the time and motion study, it is possible to derive estimates of the total average cost for treating a postabortion patient per unit of time (commonly the cost per bed minute) or the average cost per patient treated in a facility. These costs are then compared before and after changes have been made in the case management protocols for postabortion patients, in order to estimate the impact of improvements on the facility's costs.

An overview of operations research studies that investigated the costs of providing postabortion care in A frica and Latin A merica was presented by Tim King (King et al.). Through a review of 21 studies from six countries (including nine from M exico and seven from Kenya) that utilized the I pas cost study methodology, comparisons were made on the average length of stay and the total costs of using MVA as compared to sharp curettage. In general, switching to MVA and reorganizing services reduced the average length of stay by about 30 percent and the overall treatment costs to each facility by approximately 61 percent. An analysis of studies that are comparable in terms of their design and data collection methods found that when MVA is used there is a 49 percent reduction in the average length of stay and a

*See, for example, Brooke J ohnson et al. 1993. 'Costs and resources utilized for the treatment of incomplete abortion in Kenya and Mexico," Social Science and Medicine 36, no. 11. 
23 percent drop in treatment costs. Most of the savings attributed to the improvements in postabortion service delivery are directly due to the reduction in the length of stay (and corresponding decrease in staff time and overhead costs associated with each hospitalization). King and his colleagues noted that although the reduced length of stay could be due in part to a shorter recuperation period when local anesthesia is used, the reorganization of services from in-patient to out-patient settings in most studies played an important role in reducing the average length of stay.

A detailed application of the I pas cost methodology to an ongoing program to improve postabortion services in a large public-sector hospital in Oaxaca, M exico was discussed by Carlos Brambila (Brambila et al.). The improvements to postabortion services in the Oaxaca general hospital are similar to changes made in other settings. MVA instruments were introduced, counseling procedures were emphasized, and linkages with hospital family planning services were established through discussions with staff. The impact of these improvements on the quality of care provided to postabortion patients is comparable to the changes observed in other settings. For example, the use of MVA increased from 13 percent of the cases to 65 percent. Communication with patients about treatment, recuperation, and family planning increased both in frequency and in the range of issues discussed. As a result of improved counseling and integrated services, contraceptive prevalence among discharged patients increased from 28 percent to 44 percent.

The costs savings associated with these service delivery improvements are equally impressive. The total cost per patient was reduced by 32 percent, from $\$ 265$ to $\$ 180$ (including the costs associated with introducing the improvements). The most significant savings were achieved in the use of instruments, medicines, and supplies; costs were reduced by almost two-thirds, from $\$ 92$ before the study to $\$ 32$ after services were improved. A nother significant change in costs before and after the intervention is in bed time use, which was reduced from $\$ 150$ to $\$ 85$. This savings is directly attributable to the reduction in the length of stay that occurred during this study (from roughly 30 hours per patient before the study to 20 hours after the intervention).

The contribution to the development of the I pas methodology by the Oaxaca, Mexico cost study is found in its analysis of the allocation of staff time during the different stages of care. A ratio of personnel time was produced that indicates the personnel effort required to provide medical care at each of the station areas. Use of this ratio reveals that prior to the intervention the personnel effort required for patient assessment was 49 percent higher than after the intervention - clearly indicating that more efficient use of staff occurred as a result of the service delivery improvements. Pursuing this line of inquiry, the study shows that although the amount of staff time decreased, the amount of time by category of staff varied substantially. For example, after the intervention, doctors participated more during the ultrasound diagnostics but less during the time patients spent waiting in beds prior to treatment. In a similar manner, the reliance on MVA during surgical intervention meant that nurses devoted proportionally more time to the care of the patient than the doctors: the 
amount of doctor time during the procedure decreased by 24 minutes per patient while the amount of nursing time increased by approximately 10 minutes. While the saving in personnel time is small as compared with other sources of savings, the detailed analysis shows that the allocation of staff time is more efficient and relies less upon specialized medical personnel during non-diagnostic or therapeutic stages of care.

A nother example of an analytic variation on the I pas methodology was presented by Laila Nawar, based on a study in Egypt ( $N$ awar et al.). As was the case with the Oaxaca study, the cost analysis reported on by Nawar was part of a larger program to improve the postabortion medical care provided to Egyptian patients. Two of the ten hospitals involved with the postabortion improvement program were selected as sites for the cost analysis. These two hospitals are typical facilities of the Egyptian Ministry of Health and Population, one being a medium-sized general hospital, the other a smaller district hospital. Both sites demonstrated service delivery improvements comparable to those found in the 0 axaca study. Prior to the postabortion operations research studies, these two sites were providing services at a very low level of quality. For example, approximately two-thirds of the postabortion patients had a D\&C with no anesthesia at the district hospital, and aseptic procedures were not commonly adhered to in either site.

Using the I pas methodology, Nawar and her colleagues reported a 32 percent increase in the costs per postabortion patient in the district hospital and 8 percent in the general hospital (when the MVA cannulae are discarded after a single use, which is government policy); assuming multiple use of the cannulae, the cost increase in the district and general hospitals were reduced to approximately 6 percent. The hypothetical cost savings from reusing the cannulae essentially compensated for the increased costs of using pain control medication and antiseptic supplies, as personnel time was little affected by the postabortion care intervention. Reductions in the length of stay at the hospitals occurred in this study (a 69 percent reduction in the district hospital and a 30 percent reduction in the general hospital), but the savings in direct fixed costs associated with the shorter length of stay did not offset the increased costs in supplies, materials, and medications. The Egypt cost study therefore clearly shows that in settings with substandard postabortion quality, improvements will carry a price.

The changes in absolute costs associated with the introduction of service improvements do not reveal the potential cost savings when assessed in comparison to indicators of enhanced quality of care. Nawar and colleagues report that there are substantially different measures of the cost-effectiveness of postabortion services depending upon the outcome indicator chosen and the costing characteristics of each site. For example, although there was an overall 10 percent cost savings in the interventions' effectiveness in reaching more women about family planning use, in the general hospital there was a 21 percent cost-effectiveness savings, whereas in the district hospital there was actually an increase in the cost per patient. The intervention demonstrated its cost-effectiveness in reaching women with information about follow-up appointments in both sites. 
Andy Thompson's critical overview of the three cost study papers engendered a lively discussion about the development of this specialized operations research methodology. The savings generated by changing postabortion treatments are a type of "opportunity savings" (freeing up resources for use elsewhere) as opposed to reductions in costs that could lead to overall reductions in hospital expenditures. This has raised the need for future postabortion cost studies to demonstrate how resources that are freed-up by reduced length of stay can be reallocated and whether or not the types of costs that have been investigated are actually the most significant costs from a hospital manager's point of view (i.e., those under his control). For example, are the cost savings on routine cases being converted into making more resources available for the treatment of patients who present with severe complications? To the extent that postabortion cost studies can provide answers to these types of questions, the data they produce will have direct relevance to the management of medical services, and provide useful information for health care policy development.

\section{Decentralization and Scaling-U p of Postabortion Care Services}

The sites most commonly selected for experimenting with improved postabortion care services documented in the large majority of studies have been public-sector hospitals, with care provided by teams of physicians and nurses. However, postabortion care using MVA with local anesthesia can also be safely provided by trained medical staff in primary care settings. Foll owing up on the Safe Motherhood I nitiative's experience with training midwives and other paramedical personnel, contemporary postabortion studies have begun to explore alternative service delivery strategies for providing safe and accessible emergency medical care.

Discussing an attempt to decentralize postabortion care services within rural areas of Ghana, Victor Ankrah reported on the use of community midwives as postabortion care providers (A nkrah et al.). A lthough Ghanaian law regarding abortion allows registered medical personnel in certified facilities to induce an abortion under a variety of circumstances, many women continue to suffer the consequences of unsafe abortion. It is widely acknowledged in Ghana that unsafe abortion is one of the primary causes of pregnancy-related mortality in the country, while the availability of emergency medical services is extremely limited in rural areas. Ghana's Ministry of $\mathrm{H}$ ealth included references to providing accessible and safe postabortion services in its $1996 \mathrm{~N}$ ational Reproductive Health Service Policy and Standards. The implementation of this policy has included an experimental component for training some of the country's 6,000 community midwives as postabortion care providers.

A pre- and post-test controlled study design was employed to examine improvements in the quality of care associated with training community midwives in postabortion care. Both providers in local hospitals (who supervise the community midwives) and the midwives themselves were interviewed, along with women who arrived at one of the six district hospi- 
tals for treatment of postabortion complications. Following the baseline data collection, 40 midwives and four physicians were trained together in improved case management procedures. Many benefits were gained by training the midwives along with their physician supervisors, including the development of a supportive and trustful supervisory system for the decentralized postabortion services.

The results from the Ghana midwives study show that by including paramedical staff who live in the communities, access to postabortion services is greatly improved: waiting time before treatment for women who sought care from midwives averaged 90 minutes, as compared to an average of 220 minutes among women who sought care at a district hospital. Out-of-pocket expenses were less for the patients treated by midwives, and women reported that they felt comfortable with the midwives' skills and abilities. Midwives successfully used MVA, with no procedural complications being observed, and all of the instruments were consistently processed according to strict aseptic protocols. In addition to demonstrating their ability to follow case management protocols, the community midwives also ensured that follow-up appointments with their patients were routinely observed, including the provision of postabortion family planning. The study concludes that the collaborative links with district hospitals (where physician supervisors reside) established with the postabortion training have provided the midwives with opportunities to improve their professional skills in other areas. In addition, their close proximity to the communities where they work, and their in-depth understanding of the problems women face, have led many of the midwives to convene community education activities to raise women's and men's awareness of the issues of unsafe abortion and unwanted pregnancies.

An example of using traditional midwives as postabortion care providers was presented by Deborah Billings, based upon results from an ethnographic study in rural Morelos, Mexico (Billings et al.). A s in Ghana, complications of unsafe abortion are responsible for a significant proportion of maternal mortality: routinely collected statistics from public-sector facilities suggest that abortion-related complications represent the third or fourth most important cause of maternal mortality in M exico. In large part this is because rural women have limited access to emergency medical services. Despite the Mexican government's attention to improving the skills of traditional midwives, prior to this operations research study no attempt had been made to include training on postabortion care for these lay health care providers. Billings and her colleagues conducted a qualitative field study of traditional midwives' concepts and experiences regarding abortion, and explored differences in midwives' knowledge about abortion before and after their participation in a postabortion care training program that focused on stabilization of any complications and referral for postabortion treatment.

Earlier research had indicated that midwives' knowledge about abortion complications was insufficient and inaccurate. In addition, although training for midwives was shown to improve their knowledge about a range of medical conditions, their popular beliefs about risk factors for a miscarriage (such as passing by a cemetery or washing shawls) were little changed. The orientation of the postabortion training for these traditional midwives was to 
add to their existing treatments, while discouraging potentially harmful beliefs. Traditional midwives therefore practice rituals imbued with symbolism and involving herbal remedies and physical therapy, while integrating these within the modern medical system's reliance upon warning signs and referral protocols. Billings and colleagues point out that traditional midwives require training and evaluation models different from those used to teach hospital-based personnel. The integration of popular belief systems and indigenous pharmacopeia within the Western conceptual framework of warning signs and follow-up care needs to be better understood before more effective use can be made of traditional midwives.

The strong normative sanctions against induced abortion in the Morelos communities, however, were found to constrain the effective use of traditional midwives as postabortion care providers. These constraints particularly hinder the development of a referral network from the community to the nearby hospital for the prompt treatment of incomplete induced abortion. Midwives' fear of being labeled "abortionists" reportedly inhibited some from readily providing emergency medical treatment. In addition, midwives have experienced feelings of ostracism and condemnation by physicians in modern hospitals (where not all staff were familiar with and supportive of the midwives' role) when they accompany women for emergency medical care. These perceptions and experiences contribute to the difficulties of creating a viable referral network for incomplete abortions in Morelos. Conducting joint workshops with midwives and physicians, such as was done in Ghana, is one approach to breaking down barriers between the traditional and modern health care systems.

A third example of improving access to postabortion services through the use of new categories of health personnel was presented by A chola Ominde (F rench et al.). To increase the number of facilities where postabortion services (using MVA) are available, Kenya's M inistry of Health has employed operations research to examine the feasibility of introducing improved services into district and primary health care centers. The decentralization of services required training clinical officers (mid-level paramedical staff who primarily assist physicians, but may be assigned to a post where they are the senior medical officer) in postabortion treatment, including the use of MVA. In larger hospitals clinical officers routinely provide out-patient services, including the management of postabortion cases. Prior to the operations research study conducted by 0 minde and his colleagues, there were no guidelines for having clinical officers provide postabortion services in settings where senior medical specialists are unavailable as back-up.

A clinical officer and a nurse from each site were trained in a team approach to providing postabortion services. Changes in the attitudes of medical staff regarding the suitability of having mid-level medical personnel provide postabortion treatment were assessed by interviewing policymakers from the Ministry of Health, representatives from professional organizations, all clinical officers, and physicians and nurses working in the three district hospitals before, and two months after, the training programs. The results from these interviews indicate that all respondents felt clinical officers had shown themselves to be capable of delivering high-quality MVA services for uncomplicated cases of incomplete abortion. For 
example, there was a substantial increase in the number of medical staff and policymakers who identified uterine evacuation as a procedure within a clinical officer's scope of work (from 48 percent before the intervention to 86 percent after). Medical personnel working in tertiary care hospitals reported a reduction in their postabortion caseload as more cases were being treated in the district hospitals and primary care centers. Additionally, medical staff reported reduced bed occupancy by postabortion patients and reduced utilization of medicines and supplies in the operating theater as a result of shifting the treatment of relatively uncomplicated postabortion cases from tertiary care facilities to the district and primary care levels. Based on the findings of this study, recommendations are being considered by the Ministry of $\mathrm{H}$ ealth to introduce changes in government policy to guarantee clinical officers the protection needed to legally perform MVAs. The logistics of ensuring a supply of MVA equipment to lower levels of the health care system are also being clarified as the next step in decentralizing postabortion services in Kenya.

The expansion of postabortion services that pilot studies have shown to be feasible is clearly the next step in the evolution of improved postabortion care. Issues surrounding the scaling-up of postabortion operations research studies are beginning to be understood by researchers and program managers alike, as the first round of post-ICPD studies have been completed. Dale Huntington reported on the experience in Egypt, where a series of postabortion operations research studies have been conducted, beginning with a small pilot study in 1993, followed by a larger, scaled-up study and other policy-related research (Huntington and Nawar).

Two sets of circumstances surrounding postabortion care operations research have profound implications for the movement from operations research into fully developed health care programs. The first concerns the sensitive nature of abortion, particularly in settings where access to services is legally restricted and socially sanctioned. By placing the issues under investigation clearly within the medical domain, the concept of postabortion care has made an important contribution to the field of women's reproductive health. Nevertheless, the subject of postabortion care is prone to misconceptions that inhibit the work of advocates within both the government and the medical community.

The second set of circumstances concerns the supply of MVA instruments. The use of donated commodities is an expedient mechanism for the conduct of pilot studies, or even a small-scale expansion. It is unrealistic to develop extensive postabortion care services that depend upon donated commodities, particularly commodities that the US Agency for International Development is unable to provide. A ttention must be given by researchers and program managers to ensuring a continuous supply of MVA instruments at all stages of a program's development. The constraints acting upon the shift from using donated supplies to having commercially available commodities for the postabortion program are not fully understood by researchers.

Huntington and his colleagues have found that within the largely conservative Egyptian society the expansion of postabortion services will never be a widely recognized introduc- 


\section{Figure 8}

Framework for Introducing Program

Improvements in Postabortion Care

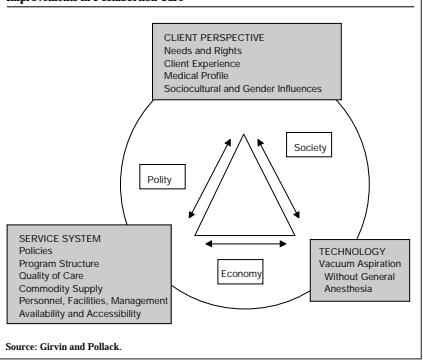

tion program, along the lines of other population-sector innovations. They suggest that this will be the case in other settings where similar legal and social restrictions exist on abortion. In settings such as these a pragmatic approach is required to further the goal of institutionalization. The creation of partnerships with other safe motherhood programs, establishing linkages with postpartum family planning programs, and consistent attention to expanding the range of informed constituencies within the medical community are all required to sustain the development of services.

In their review of the operations research experience with decentralizing and scaling-up postabortion care studies, Sally Girvin and A my Pollack emphasize that these are two distinctly different programmatic initiatives. Decentralization occurs when the authority to manage and deliver services exists apart from central control. Scaling-up is a process of integrating change on a broad basis into an existing infrastructure. The problem of how to increase access to postabortion care services can be addressed by decentralizing services or by scaling-up a pilot operations research study. An essential point in either case is that increased access to services is accomplished within a context that explicitly incorporates elements that either maintain or improve the quality of care provided to patients.

The range of elements that must be considered when programs seek either to decentralize or to expand a pilot study goes beyond the elements of a quality of care framework, how- 
ever. This is because quality of care is only one aspect of a comprehensive service delivery scheme. The range of elements that should be considered when introducing expanded postabortion services is illustrated by Girvin and Pollack's adaptation of the WHO strategic approach to contraceptive introduction (see Figure 8). The interactive nature of the three service delivery elements - client perspective, service system, and technology - is a fundamental dynamic of delivering health care services. The interface between the service system and the client includes provider attitudes, a critical aspect of service provision in light of the political, socio-cultural, and economic environment surrounding postabortion care.

The WHO approach to understanding the development of health care services draws attention to issues surrounding the decentralization of postabortion services. Programs must distinguish between initiatives that seek to decentralize a technology (MVA) and those that develop autonomous centers of locally based authority for the delivery of health care services. The ability to create policies on costs, commodity supply, personnel, and management systems in support of locally controlled services is an indication of a decentralized program. Postabortion operations research studies that examine elements of decentralization need to pay attention to these other elements, in addition to the effort to make MVA technology more widely available. In a similar manner, scaling-up a postabortion pilot study implies much more than simply expanding the number of service delivery points where MVA technology is available. Services are best established by applying findings from research conducted in increasingly more complex environments, including that of a demonstration project. In closing, Girvin and Pollack urged health care professionals to address the issues of MVA supply from a human rights perspective, and to confront the stigma related to postabortion services in order to advance the availability of safe and humane reproductive health care.

\section{Ethical Dimensions of P ostabortion Care Operations R esearch}

The ethical conduct of operations research related to women's reproductive health care is a critical element of fieldwork. The $1964 \mathrm{Helsinki}$ Declaration provided clear guidance on the subordination of the interests of science to the welfare of research subjects. A consensus on the nature of ethical standards has evolved to include the following three fundamental principles: respect for persons, including the right of self-determination of capable individuals and protection of persons with impaired or diminished autonomy; beneficence, which implies an ethical obligation to maximize benefits and minimize harm and also includes notions of non-maleficence; and justice for research subjects, to be attained through equal treatment of all subjects. Karin Ringheim reviewed these fundamental ethical considerations in the context of postabortion operations research and laid out a series of questions that were examined by discussion groups following her presentation (Ringheim).

At a roundtable discussion on ethics, population, and reproductive health, sponsored by Columbia University and UNFPA prior to the 1994 ICPD, participants examined the 
Helsinki Declaration in light of contemporary reproductive health research, and produced a "Declaration of Ethical Principles" that embodies the aforementioned ethical principles while setting higher standards of ethical conduct for researchers. In her thought-provoking paper, Ringheim reviewed these principles as they relate to postabortion care research.

The challenge for operations research is to ensure that strict ethical guidelines, of the sort outlined by Ringheim, are adhered to by both interviewers and service providers. The requirements for confidentiality and valid informed consent do not typically draw attention to the importance of interviewer selection and often are not addressed in training programs. Indeed, guidelines for the ethical training of interviewers and providers are notably lacking for the field of reproductive health operations research. Several issues are unresolved and poorly documented in the literature. For example, obtaining informed consent is not as straightforward as it may seem. Western, highly individualized language concerning the right to withdraw from a study, the right to refuse to answer questions, and so on is not easily adapted into non-Western, traditional cultural settings. The content of these statements needs to be clarified within each setting, and respondents should review and agree upon procedures to be followed. Supervision and close monitoring of client- provider interactions are necessary to ensure that interviewers and providers adhere to ethical procedures and do not abuse their power to influence and subvert client choice.

The importance of ensuring the ethi-

1. Because reproductive health is an important social good, promoting reproductive health and improving conditions for its attainment are ethical obligations.

2. Justice in reproductive health requires an equitable allocation of benefits and responsibilities related to reproductive decisions, including decisions about whether or not to have children.

3. For actions and practices to be ethical, persons must be treated with respect, and the autonomy of individuals must be respected.

4. Ethically sound reproductive health programs and policies are ones that result in a preponderance of desirable consequences rather than undesirable ones.

Source: Ringheim (drawn from "The Declaration of Ethical Principles").

cal treatment of women by service providers is an unexplored area for operations research, where the focus has been on the ethical conduct of data collection activities. As Ringheim asks in her paper, "H ow do we change a lifetime of paternalism toward women in which the provider believes that he or she knows best? More specific to the provision of postabortion care, how do we alter the hostility and negligence that may await clients, based on providers' negative attitudes toward abortion?" These issues come to the fore in the administration of pain control medication, in the ethical necessity for the patient to be able to control her treatment, and in the responsibility of the service provider for ensuring that services do not result in physical or mental discomfort, harm, or 
danger. Several operations research studies have suggested that the treatment of pain, or the lack of pain control treatment, is an ethical issue that investigators of postabortion care need to address. Indeed, the discussion groups that followed Ringheim's presentation reiterated the point that the administration of pain control medication was more an issue for service provision than research methodology.

The conduct of postabortion operations research with unmarried or adolescent women, which occurs in many settings, poses several ethical considerations particular to such subjects. It may be difficult to convince local providers that these women should participate in a study, or, if they do participate, that they have the same rights to informed consent and confidentiality as do married, older women. Attention to these ethical considerations should be increased with these subjects because of their heightened vulnerability to physical or psychological harm if their pregnancy or abortion is disclosed to family members. In some settings adolescents will be more apt to seek care in the private sector so as to ensure confidentiality. As was pointed out earlier in the meeting, however, postabortion operations research has not typically examined service delivery issues outside the public sector. Thus the study of postabortion services for adolescents challenges researchers to expand into new service delivery systems, as well as to establish the highest ethical standards for both service providers and data collection agents.

\section{Future Directions for Postabortion Care Operations R esearch}

A second set of discussion groups examined issues pertaining to future topics for postabortion care operations research. J anie Benson began by reviewing progress made and suggesting future directions for the field (Benson). The themes of her paper were expanded upon in the discussion groups. In the period since the lifting of the Mexico City restrictions on abortion research, a remarkably quick transformation has occurred in perceptions about the suitability of studying postabortion issues. Operations research has been used to diagnose clinical and other obstacles to providing high-quality, holistic reproductive health care, to influence policy, and to test alternative service delivery models. Although much knowledge has recently been generated, several unexplored areas remain for the next round of postabortion studies.

Most operations research studies have taken place in hospitals, typically in urban areas. As services move out of hospitals to health centers and the primary care level, there is increasing need to understand the requirements for paramedical personnel who provide postabortion services in outlying areas. A few of the studies reported on in the meeting examined this issue, but given the worldwide move toward decentralization of health care services, far more experience is required before program managers will be assured of how to expand services to rural areas and to the urban poor. The role of the private sector is another underexplored area related to the expansion of postabortion services. 
A second set of neglected issues concerns women's perceptions of incomplete abortion and unwanted pregnancy. An understanding of the interrelationships between contraceptive use dynamics (including emergency contraception), unwanted pregnancy, and induced abortion is central to breaking a cycle of repeat abortions, but reports from the field are not readily available. There is a need for qualitative research on these issues, particularly studies that suggest programmatic interventions responsive to women's perceptions and their needs. A related set of issues concerns the involvement of a woman's social network, particularly her husband or partner. Some projects have begun to explore the issue of male involvement, and these initial efforts have produced promising results. These studies need to be replicated in different settings to expand our understanding of ways to involve men in an ethically responsible manner with the postabortion care provided to women.

The involvement of other members of a woman's social network in postabortion care requires the identification of appropriate outcome indicators for measuring program impact. There has been limited experience with longer-term follow-up studies, in part reflecting the nature of the field. There are also a number of serious ethical considerations in following-up postabortion patients that longitudinal studies must resolve. Although studies of the reduction of abortion-related mortality will go beyond the scope of an operations research agenda, there is a need to investigate the impact of improving postabortion services on reducing repeat abortions and on sustained use of contraceptive methods.

The ability of operations research to move beyond the conduct of pilot and demonstration studies will become a pressing need in the next few years. Scaling-up strategies need to be elaborated upon, and successful models should be disseminated. The global database project, DATAPAC, is important in this regard. The creation of diverse partnerships within health-and population-sector service delivery agencies is clearly important in moving postabortion care out of the research domain and into an ongoing program. Establishing a sustainable supply of MVA instruments will require partnerships with private-sector firms, while lobbying for donor funds for training and systems development requires consistent governmental support. This advocacy role is an emerging area of importance for the field of operations research, and the special circumstances surrounding postabortion service provision require the development of a sensitive dissemination and communication strategy. Resources and technical assistance are required to ensure that the results from ongoing postabortion operations research are widely disseminated and utilized. This requires the sustained commitment of governments and donors to the goals of the ICPD. Tremendous advances have been made in the improvement of this area of women's reproductive health care. The challenge will be to expand beyond this first round of studies and to institutionalize the provision of safe and humane postabortion care for all women in need. 


\section{Papers Presented}

For copies of papers please direct requets to the principal author (refer to the list. of participants for complede contact information).

A bdel-Tawab, Nahla, Dale Huntington, Ezzeldin Osman Hassan, Hala Youssef, and Laila Nawar, "Effects of husband involvement on postabortion patients' recovery and use of contraception in Egypt"

Ankrah, Victor, Kathlyn Ababio, Deborah Billings, Joseph Taylor, Traci Baird, and Steve Ntow, "Community midwives in Ghana offer comprehensive postabortion care"

Benson, J anie, "Future directions in postabortion care research"

Benson, J anie, Victor H uapaya, Marian A bernathy, and J ohn Naghata, "Provider practices and patient perspectives in an integrated postabortion care model in Peru"

Billings, Deborah, X ochitl Castaneda Camey, Xochitl R omero, Virginia Chambers, A ndrea Saldana, Hector M. Alvarez Valero, Julia Blanco, and Patricia Voorduin, "Traditional midwives and postabortion care services in Morelos, Mexico"

Brambila, Carlos, Cecila Garcia-Barrios, and Angela M. Heimburger, "Estimating costs of postabortion services at A urelio Valdivieso General H ospital, Oaxaca, Mexico"

Diaz, Juan, Mariel Loayza, Yamile Torres de Yépez, Oscar Lora, Fernando Alvarez, and Virginia Camacho, "Evaluation of a strategy for improving the quality of services and contraceptive acceptance in the postabortion period in three public-sector hospitals in Bolivia"

French, Bertha, Njoroge Waithaka, and A chola Ominde, "Management of incomplete abortion in Kenya by clinical officers: A pilot study"

Fuentes Velazquez, Jaime A., Deborah L. Billings, and J orge Arturo Cardona Perez, "Women's experience of pain during the postabortion period in Mexico"

Ghosh, Anita, Bibiane Kone, Jean Lankoande, and Placide Tapsoba, "Introducing improved postabortion care into maternity services in Burkina Faso"

Greenslade, Forrest C., Judith Winkler, and Ann H. Leonard, "A framework for evaluating the quality of postabortion care services"

Huntington, Dale and Laila Nawar, "Introducing improved postabortion care in Egypt: Moving from a pilot study to large-scale expansion"

Huntington, Dale, Laila Nawar, Ezzeldin Osman Hassan, Hala Youssef, and Nahla Abdel-Tawab, "A descriptive study of the postabortion caseload in Egyptian hospitals"

Johnson, Brooke, Michael T. M bizvo, Tsungai Chipato, and Felicity Zawaira, "Conducting follow-up with postabortion women in Zimbabwe: Some preliminary descriptive findings"

Khan, M. E., S. Rajagopal, Sandhya Barge, and Nayan Kumar, "Situation analysis of medical termination of pregnancy (MTP) services in Gujarat, Maharashtra, Tamil Nadu, and Uttar Pradesh"

King, Tim, Janie Benson, and Karen Stein, "Comparing the cost of postabortion care in Africa and Latin A merica: The DATAPAC Project"

Langer, A na, Cecilia Garcia-Barrios, A ngela Heimburger, Lourdes Campero, Olivia Ortiz, Carmen Diaz, Vilma Barahona, Francisca Ramirez, and B eatriz Casas, "I mproving postabortion care in a public hospital in Oaxaca, Mexico" 
Nawar, Laila, Dale Huntington, and Mohammed Naguib, "Cost-effectiveness of postabortion services in Egypt"

Pile, John, A rzum G. Ciloglu, Levent Çagatay, and Cidgem Bumin, "The quality of abortion services in Turkey"

Ringheim, Karin, "Toward an understanding of ethical issues in postabortion care research - A background discussion paper"

Solo, Julie, A chola Ominde, Margaret Makumi, Deborah Billings, and Colette Aloo-Obunga, "Creating linkages between incomplete abortion treatment and family planning services in Kenya: What works best?"

Stein, Karen, " Postabortion care: Standardizing instruments and the postabortion care database" 


\section{Participants}

\section{Nahla Abdel-Tawab}

Country Fellow

Population Council

6A Bahieddin Barakat Street, Giza

PO Box 115, Dokki 12211, Cairo, Egypt

tel: $202-573-8277 / 570-1733 / 571-9252$

fax: 202-570-1804

e-mail: ntawab@pccairo.org

\section{Marian Abernathy}

Program A ssociate for Latin A merica I pas

303 E. Main Street, PO B ox 999

Carrboro, NC 27510

tel: $919-967-7052$

fax: 919-929-0258

e-mail: mariana@ipas.org

\section{Victor Ankrah}

Ministry of $\mathrm{H}$ ealth/E astern R egion

PO Box 175

Koforidua, Ghana

tel: $233-81-23351$

fax: 233-81-23351

e-mail: vankrah@africaonline.com.gh

\section{I an Askew}

Project Director, A frica OR/TA

Population Council

Multichoice Towers, Upper Hill

PO Box 17643, Nairobi, Kenya

tel: $254-2-713480$

fax: 254-2-713479

e-mail: iaskew@popcouncil.or.ke

\section{Karen B eattie}

Program Manager for Research

AVSC International

79 Madison Avenue

New York, NY 10016

tel: $212-561-8458$

fax: $212-779-9439$

e-mail: kbeattie@avsc.org

\section{Janie Benson}

Director, Health Systems Research

I pas

303 E. Main Street, PO B ox 999

Carrboro, NC 27510

tel: $919-967-7052$

fax: 919-929-0258

e-mail: bensonj@ipas.org
Deborah Billings

Research A ssociate

Ipas

303 E. Main Street, PO Box 999

Carrboro, NC 27510

tel: $919-967-7052$

fax: 919-929-0258

e-mail: debbieb@ipas.org

\section{Carlos B rambila}

Associate

Population Council

Escondida 110, Col Villa Coyoacan

Mexico, DF 04000, Mexico

tel: 525-554-0388, 554-8610

fax: 525-554-1226

e-mail: cbrambila@laneta.apc.org

\section{George Brown}

Vice President

Population Council

One Dag Hammarskjold Plaza

New York, NY 10017

tel: $212-339-0500$

fax: 212-755-6052

e-mail: gbrown@popcouncil.org

\section{Levent Çagatay}

Program A ssociate

AVSC International

A bidin Daver S. 7/6, Cankaya 06550

Ankara, Turkey

tel: $90-312-4411761$

fax: $90-312-4414674$

e-mail: Icagatay@avsc.org.tr

Margaret Catley-Carlson

President

Population Council

One Dag Hammarskjold Plaza

New York, NY 10017

tel: $212-339-0500$

fax: 212-755-6052

e-mail: mcatleycarlson@popcouncil.org

Richard Columbia

Director of Evaluation

Pathfinder International

9 Galen Street

Watertown, MA 02172

tel: $617-924-7200$

fax: 617-924-3833 


\section{Kurus Coyaji}

Director and Honorary Professor

KEM Hospital

Rasta Peth

Pune, 411 011, India

tel: $91-212-625-600$

fax: 91-212-625-603

e-mail: kurus.coyaji@sm4.sprintrpg.ems.vsnl.net.in

\section{Juan Diaz}

Senior A ssociate

Population Council

Caixa Postal $6168,13081-970$

Campinas, Săo Paulo, Brazil

tel: 55-19-2392856

fax: 55-19-2392440

e-mail: pcbrazil@turing.unicamp.br

\section{Ousseynou Faye}

\section{CEFROEP}

Clinique Gyneco-obstetrique

Hôpital A, Le Dantec,

Dakar, Senegal

\section{Michelle Folsom}

Regional ARH Advisor

USAID REDSO/ESA

PO Box 30261

Nairobi, Kenya

tel: $254-2-751613$ ext. 2459

fax: $254-2-743204$

e-mail: mfolsom@usaid.gov

\section{James Foreit}

Project Director, INOPAL

Population Council

4301 Connecticut Ave. NW

Suite 280

Washington, DC 20008

tel: $202-237-9400$

fax: 202-237-8410

e-mail: jforeit@pcdc.org

\section{Bertha French}

Program A ssociate

Ipas

303 E. Main Street, PO B ox 999

Carrboro, NC 27510

tel: 919-967-7052

fax: 919-929-0258

e-mail: frenchbm@ipas.org

\author{
Alison Friedman \\ Research Associate \\ Ipas \\ 303 E. Main Street, PO Box 999 \\ Carrboro, NC 27510 \\ tel: 919-967-7052 \\ fax: 919-929-0258 \\ e-mail: friedman@ipas.org \\ J aime Fuentes \\ Mexican Social Security Institute \\ Mier y Pesado $\# 120$ \\ Colonia de Valle \\ Mexico, D.F. 03100 , Mexico \\ tel: $525-536-8861$ \\ fax: 525-536-8861
}

\section{Cecilia Garcia-Barrios}

Consultant

Population Council

Escondida 110, Col Villa Coyoacan

Mexico, D.F., 04000 , Mexico

tel: $525-598-7556$

fax: 525-554-1226

e-mail: inopalmix@laneta.apc.org

Phyllis Gestrin

Senior Advisor in R eproductive $\mathrm{H}$ ealth

Africa Bureau, USAID

1111 North 19th Street, Room 300

Rosslyn, VA 22209

tel: $703-235-4446$

fax: 703-235-4466

e-mail: pgestrin@usaid.gov

Anita Ghosh

Program Development Officer

JHPIEGO

Brown's Wharf

1615 Thames Street, Suite 200

Baltimore, MD 21231

tel: 410-955-4413

fax: 410-955-6199

e-mail: anita@wpo.jhpiego.org

\section{Sally Girvin}

Medical Associate, PAC Program Manager

AVSC International

79 Madison Avenue

New York, NY 10016

tel: $212-561-8458$

fax: 212-779-9439

e-mail: sgirvin@avsc.org 
J oanne Gleason

Program Manager, Africa OR/TA

Population Council

One Dag H ammarskjold Plaza

New York, NY 10017

tel: $212-339-0500$

fax: 212-755-6052

e-mail: jgleason@popcouncil.org

\section{Forrest Greenslade}

President

I pas

303 E. Main Street, PO Box 999

Carrboro, NC 27510

tel: 919-967-7052

fax: 919-929-0258

e-mail: forrestg@ipas.org

\section{Gustavo Gutierrez}

Guatemalan Social Security Institute

c/o Population Council

8a Calle 14-44, Zona 13

Guatemala City, 01013 C.A., Guatemala

tel: $502-3-32-38-48$ / 32-23-65

fax: 502-3-62-72-27

e-mail: popcouncil@guate.net

\section{Nicole Haberland}

Program Manager

Gender, Family, and Development

Population Council

One Dag H ammarskjold Plaza

New York, NY 10017

tel: 212-339-0500

fax: 212-755-6052

e-mail: nhaberland@popcouncil.org

\section{Ezzeldin Osman Hassan}

Executive Director

Egyptian Fertility Care Centre

2A EI Mahrouki St. 7th floor

Mohandiseen, Cairo, Egypt

tel: 202-347-0674

fax: 202-346-8782

\section{Angela Heimburger}

Consultant

Population Council

Escondida 110, Col Villa Coyoacan

Mexico, D.F. 04000 , Mexico

tel: 525-554-0388

fax: 525-554-1226

e-mail: pcmexico@popcouncil.org

\section{Marge Horn}

Office of Population

USAID/G/A\&D/POP

SA 18 Room 809

Washington, DC 20523-1819

tel: $202-712-4757$

e-mail: mhorn@usaid.gov

\section{Victor Huapaya}

Population Council

Paseo Padre Constancio Bollar 225

El Olivar de San Isidro L-27

Lima, Peru

tel: $511-442-04-48$

fax: 511-440-06-35

e-mail: postmast@pclima.org.pc

\section{Dale Huntington}

Senior Program A ssociate

Population Council

6A Bahieddin Barakat Street, Giza

PO Box 115, Dokki 12211, Cairo, Egypt

tel: $202-573-8277 / 570-1733 / 571-9252$

fax: 202-570-1804

e-mail: dhunt@pccairo.org

\section{Anrudh J ain}

Director of Programs

Population Council

One Dag Hammarskjold Plaza

New York, NY 10017

tel: 212-339-0500

fax: 212-755-6052

e-mail: ajain@popcouncil.org

\section{B arbara Janowitz}

Family Health International

PO Box 13950

Research Triangle Park, NC 27709

tel: 919-544-7040

fax: $703-516-9781$

\section{B rooke Johnson}

Deputy Director, Health Systems Research Ipas

303 E. Main Street, PO Box 999

Carrboro, NC 27510

tel: 919-967-7052

fax: 919-929-0258

e-mail: rjohnson@ipas.org 
M. E. Khan

Program A ssociate and Country A dvisor

Population Council

53 Lodi Estate

New Delhi, 110003, India

tel: $91-11-461-0914 / 13$

fax: 91-11-461-0912

e-mail: pcnewdelhi@popcouncil.org

\section{Tim King}

Research Associate

I pas

303 E. Main Street, PO B ox 999

Carrboro, NC 27510

tel: $919-967-7052$ ext. 339

fax: 919-929-0258

e-mail: king@ipas.org

\section{Jean Lankoanade}

CRESAR

Clinique Gyneco-obstetrique

H ôpital Yalago BP 4759

Ouagadougou, Burkina Faso

tel: $226-380419$

fax: $226-380419$

e-mail: jlankoande@minitel.refer.org

\section{Robert Leke}

Associate Professor

Universite of Yaoundé

BP 1935

Yaoundé, Cameroon

tel: $237-22-36-17$

fax: $237-23-44-51$

\section{Noel McIntosh}

President

JHPIEGO

Brown's Wharf

1615 Thames Street, Suite 200

Baltimore, MD 21231

tel: $410-955-8558$

fax: 410-955-6199

e-mail: nmc@jhpiego.org

\section{E sther Muia}

Associate, Reproductive $\mathrm{H}$ eal th $\mathrm{P}$ rogram

Population Council

Multichoice Towers, Upper Hill

PO Box 17643, Nairobi, Kenya

tel: $254-2-713480$

fax: 254-2-71-3479

e-mail: emuia@popcouncil.or.ke

\section{Donna Nager}

Program Manager, ANE OR/TA

Population Council

One Dag Hammarskjold Plaza

New York, NY 10017

tel: 212-339-0500

fax: 212-755-6052

e-mail: dnager@popcouncil.org

\section{Laila Nawar}

Host Country A dvisor

Population Council

$6 \mathrm{~A}$ Bahieddin Barakat Street, Giza

PO Box 115, Dokki 12211, Cairo, Egypt

tel: $202-570-1733$

fax: 202-570-1804

e-mail: Inawar@pccairo.org

\section{Achola Ominde}

MCH/FP Manager

Division of Primary $\mathrm{H}$ ealth $\mathrm{C}$ are

PO Box 43319

Nairobi, Kenya

tel: $254-2-716812$

fax: $254-2-716814$

\section{Emma Ottolenghi}

Consultant

Population Council

PO BOX 308

Waterbury Center, VT 05677

tel: 802-244-8407

fax: 802-244-8302

e-mail: emmao@igc.org

\section{Amy Pollack}

President

AVSC International

79 Madison Avenue

New York, NY 10016

tel: $212-561-8458$

fax: 212-779-9439

e-mail: apollack@avsc.org

\section{Hafizur Rahman}

Institute of Research for Promotion of Essential

and Reproductive Health (BIRPERHT)

House \#195, Road 9A

Dhanmondi R/A Dhaka-1209

Bangladesh, GPO Box 279

tel: $880-2-911-0792$

fax: $880-2-911-3034$

e-mail: birperht@citechconet 


\section{Karin Ringheim}

Senior Technical Advisor, Operations Research USAID

G/PHN/POP/R

1300 Pennsylvania Avenue

Washington, DC 20523-3061

tel: 202-712-4758

e-mail: kringheim@usaid.gov

\section{Khama Rogo}

Center for the Study of A dolescence

Kabarnet R oad

Nairobi, Kenya

tel: 254-56-29-01

fax: 254-57-02-54

\section{Julie Solo}

Staff Program A ssociate

Population Council

Multichoice Towers, Upper Hill

PO Box 17643

Nairobi, Kenya

tel: $254-2-713480$

fax: 254-2-713479

e-mail: jsolo@popcouncil.or.ke

\section{Karen Stein}

Progam A ssociate, International Programs Division

Population Council

One Dag Hammarskjold Plaza

New York, NY 10017

tel: 212-339-0500

fax: 212-755-6052

e-mail: kstein@popcouncil.org

\section{Placide Tapsoba}

Program Associate, Africa OR/TA Project

Population Council

Villa Nx4 Stele Mermoz

Route de la Pyrotechnie

BP 21207

Dakar, Senegal

tel: 221-241-993/4

fax: 221-241-998

e-mail: pcdakar@sonatel.senet.net

\section{Kathryn Tolbert}

Program Associate

Population Council

Escondida 110, Col Villa Coyoacan

Mexico, D.F. 04000 , Mexico

tel: 525-554-0388

fax: $525-554-1226$

e-mail: ktolbert@laneta.apc.org

\section{Andy Thompson}

Research Associate

Family Health International

Nairobi, Kenya

tel: $254-2-713-480$

fax: 254-2-213-479

e-mail: athompson@popcouncil.or.ke

\section{John Townsend}

Project Director, ANE OR/TA

Population Council

53 Lodi Estate

New Delhi, 110003, India

tel: 91-11-461-0914/13

fax: 91-11-461-0912

e-mail: pcindiareg@popcouncil.org

\section{Sandra Waldman}

Director, Office of Public Information

Population Council

One Dag Hammarskjold Plaza

New York, NY 10017

tel: 212-339-0500

fax: 212-755-6052

e-mail: swaldman@popcouncil.org

\section{Nancy Williamson}

Family $\mathrm{H}$ ealth International

PO Box 13950

Research Triangle Park, NC 27709

tel: $919-544-7040$

fax: 703-516-9781

\section{B everly Winikoff}

Director, Reproductive Health Program

Population Council

One Dag Hammarskjold Plaza

New York, NY 10017

tel: $212-339-0500$

fax: 212-755-6052

e-mail: bwinikoff@popcouncil.org 